\title{
AS AUDIÊNCIAS DE INSTRUÇÃO E JULGAMENTO POR VIDEOCONFERÊNCIA: UMA ANÁLISE EMPÍRICA ${ }^{1}$
}

\section{INSTRUCTIONAL HEARINGS BY VIDEOCONFERENCE: AN EMPIRICAL ANALYSIS}

Lucélia de Sena Alves

Mestre em Direitos Fundamentais, da linha de Direito Processual Coletivo, pela Universidade de Itaúna (2014). Professora da Escola Superior da Advocacia de Minas Gerais. Professora do curso de Graduação e Pós-graduação da PUC Minas. Membro do Instituto Brasileiro de Direito Processual (IBDP). Advogada no escritório Sena \& Alves Advocacia. Belo Horizonte/MG. E-mail: contato@luceliasena.com

RESUMO: A pandemia da Covid-19 trouxe enormes desafios aos operadores do direito, no sentido de se desenvolver soluções para a manutenção do andamento processual. Embora boa parte dos processos judiciais já tramitassem no formato eletrônico, alguns atos ainda eram realizados de forma presencial, como as audiências. O Conselho Nacional de Justiça instituiu as audiências por videoconferência. Entretanto, a análise de casos sugere a necessidade de aprimoramento destas audiências. O objetivo do presente artigo é, por meio da análise empírica de alguns casos noticiados na mídia, analisar a compatibilidade das audiências de instrução e julgamento com o devido processo constitucional.

PALAVRAS-CHAVE: audiência; instrução e julgamento; videoconferência; telepresenciais; processo na pandemia.

ABSTRACT: The Covid-19 pandemic has brought enormous challenges to law enforcement officials, in the sense of developing solutions for maintaining procedural progress. Although a large part of the judicial processes were already being processed in

\footnotetext{
${ }^{1}$ Artigo recebido em 22/12/2020 e aprovado em 06/09/2021.
} 
electronic format, some acts were still carried out in person, such as hearings. The National Council of Justice instituted hearings by videoconference. However, case analysis suggests the need to improve these audiences. The purpose of this article is, through the empirical analysis of some cases reported in the media, to analyze the compatibility of the instructional and trial hearings with the due constitutional process.

KEYWORDS: hearing; instruction and judgment; videoconference; telepresential; pandemic process.

\section{Introdução}

Um dos atos mais importantes do processo, quando há a necessidade de se produzirem provas orais ou tomar esclarecimentos acerca de perícia é a audiência de instrução e julgamento. Consistente em um ato complexo e solene em que as partes serão convocadas pelo juízo da causa para, na companhia de seus advogados, comparecerem no dia e data designados a fim de praticarem alguns atos como: tentativa de conciliação, instrução, debates orais e julgamento.

É nela em que o juízo entrará em contato direto com as provas e, em muitos casos, será o primeiro e único contato em que os sujeitos do processo terão a oportunidade de se encontrarem pessoalmente.

Mesmo com o processo digital, instituído pela Lei $\mathrm{n}^{\circ} 11.419 / 2006$, as audiências ainda ocorriam, primordialmente, de forma presencial.

Por intermédio da Resolução n ${ }^{\circ} 314$, de abril de 2020, do Conselho Nacional de Justiça, o Poder Judiciário foi autorizado a realizar as audiências por videoconferência, como forma de dar continuidade aos processos enquanto as políticas de isolamento social se fizerem necessárias, em razão da pandemia da Covid-19.

Estas audiências são apontadas como um dos fatores que contribuiu para o aumento da produtividade do Poder Judiciário em todo país. ${ }^{2}$ Segundo o Conselho Nacional de Justiça, mais de 366 mil videoconferências foram realizadas no âmbito do Poder Judiciário

Disponível em: < https://www.cnj.jus.br/com-mais-de-366-mil-videoconferencias-justica-elevaprodutividade-na-pandemia/>. Acesso em 17 maio 2021. 
e 19.616 salas de reuniões foram criadas. Em alguns tribunais, como é o caso do Tribunal de Justiça de Minas Gerais, registrou-se um aumento de $40 \%$ da produtividade.

Entretanto, enquanto magistrados e órgãos do Poder Judiciário comemoram os resultados promovidos pelas plataformas virtuais, advogados apontam algumas questões a serem aprimoradas, com base em experiências nas audiências por videoconferência.

O objetivo do presente artigo é analisar as audiências de instrução e julgamento por videoconferência, com base em alguns casos notificados na mídia e da experiência profissional das autoras, a fim de verificar a sua compatibilidade à luz do devido processo constitucional.

\section{Modelos de audiências de instrução e julgamento no sistema processual}

Existem, atualmente, 3 modelos de audiências de instrução e julgamento no sistema processual: a) as audiências presenciais; b) as audiências semipresenciais e; c) as audiências por videoconferência ou telepresenciais. ${ }^{3}$

A forma mais comum dessas audiências, até a pandemia do Covid-19 era a das audiências presenciais. Elas ocorrem na sede do juízo, na presença física dos sujeitos do processo envolvidos e das eventuais testemunhas arroladas pelas partes.

As audiências semipresenciais são aquelas em que nem todos os sujeitos do processo estarão presentes na sede do juízo. Até a pandemia, compareceriam à sede do juízo: juiz, partes, procuradores, auxiliares da justiça e, eventualmente, Ministério Público e perito. Já, as testemunhas arroladas pelas partes que residissem em comarca diversa, poderiam ser ouvidas telepresencialmente, por meio de chamada de vídeo. Evitaria, assim, a necessidade de oitiva da testemunha por carta precatória. No âmbito cível, este modelo nunca foi muito comum no sistema brasileiro, que sempre dava preferência às audiências presenciais. ${ }^{4}$

$\mathrm{Na}$ esfera penal, com a alteração do Código de Processo Penal dada pela Lei $\mathrm{n}^{\circ}$ 11.900/09, esta modalidade era mais comum no caso de réu preso (art. 185, $\S 2^{\circ}$ do CPP).

\footnotetext{
${ }^{3}$ ALVES, Lucélia de Sena; BORGES, Fernanda Gomes e Souza. As audiências de instrução e julgamento por videoconferência e o devido processo constitucional: uma análise empírica. In ALVES, Lucélia de Sena et al. 4 anos de vigência do Código de Processo de 2015. Belo Horizonte: Editora D’Plácido, 2020, 11.

${ }^{4}$ No processo penal esta modalidade ocorria mais frequentemente para o interrogatório do réu preso (art. 185, $\S 2^{\circ}$ do CPP).
} 
A Portaria Conjunta GCR/GVCR n ${ }^{\circ} 11$, de 3 de setembro de 2020, do TRT da $3^{\text {a }}$ Região ${ }^{5}$ estabeleceu uma nova modalidade de audiência semipresencial:

Art. $2^{\circ}$ Para os fins desta Portaria Conjunta, considera-se: audiência semipresencial: aquela em que as partes que alegarem falta de condições de acesso à internet e as testemunhas comparecerão à sede predial da unidade judiciária, para serem ouvidas na presença de um servidor designado para o ato, sob a presidência do juiz competente, que participará, assim como os advogados, exclusivamente por videoconferência. ${ }^{6}$

Por fim, as audiências por videoconferência são aquelas em que todos os participantes da audiência (juiz, partes, procuradores, testemunhas, auxiliares e, eventualmente, Ministério Público) estarão interligados por uma chamada de vídeo e não terão de comparecer à sede do juízo.

O art. $5^{\circ}$ da Portaria Conjunta GCR/GVCR n ${ }^{\circ} 11$, de 3 de setembro de 2020, do TRT da $3^{\mathrm{a}}$ Região $^{7}$ dispõe que: "As audiências de instrução continuarão a ser realizadas, preferencialmente, por videoconferência."

A principal diferença entre as audiências semipresenciais e as telepresenciais (ou por videoconferência) reside no fato de que, nas audiências semipresenciais, alguns participantes da audiência (testemunhas ou outras pessoas que aleguem dificuldade tecnológica) serão ouvidos na sede do juízo e seus depoimentos serão transmitidos ao vivo, na sala de audiência virtual criada pelo juízo; por outro lado, nas audiências telepresenciais, todos os sujeitos do processo participam da videoconferência, sem a necessidade de comparecerem na sede do juízo.

\section{Controvérsias da audiência de instrução e julgamento por videoconferência}

As audiências são a expressão da oralidade no processo. Elas representam o palco principal $^{8}$ do processo, em que o magistrado terá a oportunidade estar em contato direto com os seus sujeitos e testemunhas.

\footnotetext{
${ }^{5}$ Brasil. Tribunal Regional do Trabalho da $3^{\text {a }}$ Região (TRT). Portaria Conjunta n. 11, de 3 de setembro de 2020.

${ }^{6}$ Alguns juízes estão participando presencialmente destas audiências. Assim, apenas os advogados das partes participam por videochamada.

${ }^{7}$ Brasil. Tribunal Regional do Trabalho da $3^{\text {a }}$ Região (TRT). Portaria Conjunta n. 11, de 3 de setembro de 2020.

${ }^{8}$ BAHIA, Alexandre; NUNES, Dierle; PEDRON, Flávio Quinaud. Teoria Geral do Processo. Salvador: Editora JusPodivm, 2020, p. 491.
} 
O artigo abordará sobre as questões atinentes às audiências de instrução e julgamento. $^{9}$

As audiências de instrução e julgamento telepresenciais são o principal alvo de críticas por parte da doutrina, tendo muitos defendido a sua inviabilidade.

As principais dificuldades apresentadas para a sua realização são: a) a ausência de publicidade; b) dificuldade de manutenção de incomunicabilidade no depoimento pessoal; c) dificuldade de identificação das testemunhas; d) dificuldade de intimação, incomunicabilidade e inquirição das testemunhas; e) valoração da prova pelo magistrado; e f) instabilidade de tráfego de dados. ${ }^{10}$

Passa-se a analisar cada uma destas dificuldades.

Sabe-se que a regra do processo é que os seus atos processuais são públicos (art. 189). Apenas nas situações excepcionais, é que haverá restrição de acesso às partes e seus advogados (incisos I a IV, art. 189). Assim, qualquer pessoa pode assistir a audiências de processos em que não tenha sido decretado sigilo.

Assegurada constitucionalmente (art. $5^{\circ}, \mathrm{LX}$ ), a publicidade é uma garantia que possui três funções primordiais: a) proteger as partes contra juízos arbitrários e; b) permitir o controle da opinião pública sobre os serviços da justiça. ${ }^{11}$

Até o ano de 2020, as audiências de instrução e julgamento, mesmo em processos eletrônicos, ocorriam de forma presencial. Apenas quando havia a necessidade de se ouvir testemunha que residia fora da comarca é que as audiências ocorriam semi-presencialmente. A testemunha era ouvida por videoconferência e os demais sujeitos do processo permaneciam na sede do juízo na data e horários designados, onde acompanhavam o depoimento prestado por ela.

Nas audiências por videoconferência, não é possível manter a publicidade, uma vez que o link é criado pelo auxiliar da justiça e enviado aos procuradores das partes e às partes,

\footnotetext{
${ }^{9}$ As audiências de conciliação e mediação, de saneamento comparticipativo e de justificação prévia foram objeto de estudo em outro trabalho de uma das autoras. Ver: ALVES, Lucélia de Sena; SOARES, Carlos Henrique. Audiências telepresenciais na justiça cível e sua compatibilidade com o devido processo constitucional. Disponível em: 〈https://www.migalhas.com.br/depeso/331078/audiencias-telepresenciais-na-justica-civel-esua-compatibilidade-com-o-devido-processo-constitucional>. Acesso em: 14. Set. 2020.

${ }^{10}$ ALVES, Lucélia de Sena; SOARES, Carlos Henrique. Audiências telepresenciais na justiça cível e sua compatibilidade com o devido processo constitucional. Disponível em: $<$ https://www.migalhas.com.br/depeso/331078/audiencias-telepresenciais-na-justica-civel-e-suacompatibilidade-com-o-devido-processo-constitucional>. Acesso em: 14. Set. 2020.

${ }^{11}$ DIDIER JR, Fredie. Curso de Direito Processual Civil. 21. ed. Salvador: JusPodivm, 2019, p. 116. v. 1.
} 
por e-mail ou WhatsApp. ${ }^{12}$ Além disso, no dia e data designados, o auxiliar da justiça irá autorizar a entrada apenas dos sujeitos do processo e das testemunhas. Assim, não é qualquer pessoa que será autorizada a entrar na sala de audiência virtual.

O art. 459, do Código de Processo prevê que o juiz não poderá admitir perguntas que puderem induzir a resposta. Entretanto, quando se trata de audiência telepresencial, há uma enorme dificuldade de fiscalização por parte do magistrado, pois, como aponta a doutrina especializada, poderá o advogado fazer uma pergunta, e, logo após, fora do espectro da câmera, passar a resposta para a testemunha ou para a parte no depoimento pessoal. ${ }^{13}$

A identificação das testemunhas acontece sem a verificação do documento por ela apresentado e, no caso de ser determinado pelo juízo, a conferência ocorre de forma superficial pela câmera, sem que o magistrado ou servidor tenha acesso direto ao documento para a sua fiscalização. ${ }^{14}$

$\mathrm{O}$ art. 455, do CPC permite que a testemunha seja levada pela parte, independentemente de intimação, quando a sua ausência será interpretada como desistência do seu depoimento. Ocorre que, em se tratando de audiência telepresencial, se ocorrer alguma falha no sistema e a testemunha não conseguir acessar a sala de audiência virtual, isso poderá levar o juízo a interpretar como desistência da parte em sua inquirição. ${ }^{15}$

Quando se está em ambiente presencial, o contato do juízo com os sujeitos do processo e com as testemunhas tornam as percepções acerca de seu comportamento um elemento importante na valoração da prova pelo magistrado. No ambiente virtual, as partes podem estar em ambiente mais confortável e familiar, inclusive na presença de seus procuradores, o que permite que seu comportamento possa ser conduzido da melhor forma para o seu interesse no processo. ${ }^{16}$ Ao não saírem da "zona de conforto", a percepção do

\footnotetext{
${ }^{12}$ BRASIL CNJ. Manual para partes e testemunhas sobre o uso da videoconferência. Disponível em: https://www.cnj.jus.br/plataforma-videoconferencia-nacional/manual-para-partes-e-testemunhas-sobre-o-usoda-videoconferencial. Acesso em: 28. Set. 2020.

13 ALVES, Lucélia de Sena; SOARES, Carlos Henrique. Audiência telepresencial e devido processo constitucional. No prelo.

${ }^{14}$ ALVES, Lucélia de Sena; SOARES, Carlos Henrique. Audiência telepresencial e devido processo constitucional. No prelo.

15 ALVES, Lucélia de Sena; SOARES, Carlos Henrique. Audiência telepresencial e devido processo constitucional. No prelo.

16 ALVES, Lucélia de Sena; SOARES, Carlos Henrique. Audiência telepresencial e devido processo constitucional. No prelo.
} 
juízo, diante de uma versão bem prestada (nem sempre condizente com a realidade), pode ensejar em uma valoração errônea da prova.

Segundo dados de 2018, 46 milhões de brasileiros que não acessam a rede. ${ }^{17}$

Além disso, a ANATEL registrou cerca de 394 mil reclamações sobre a banda larga fixa no primeiro semestre de 2020 , no Brasil - aumento de $40 \%$ em relação ao semestre anterior. $^{18}$

A infraestrutura do país não estava preparada para enfrentar o aumento abrupto de usuários.

O art. 389 do CPC dispõe que, caso a parte não compareça à audiência de instrução, para a qual foi devidamente intimada, será aplicada a pena de confissão (art. 389, CPC). Conforme leciona a doutrina especializada, a referida pena, na audiência telepresencial, não pode ser automática, sendo indispensável se foi por dificuldades técnicas ou por falta de equipamento, por falta de energia ou até mesmo por falta de conhecimentos mínimos de informática, a pena de confissão não se faz cabível. ${ }^{19}$

\section{Análise empírica de casos}

O aumento da produtividade do Poder Judiciário está sendo comemorado pelo Conselho Nacional de Justiça, sendo as audiências por videoconferências um dos fatores apontados pelo órgão. Segundo dados apresentados no seminário online "Trabalho remoto no Judiciário: resultados do uso da plataforma Webex " ${ }^{20}$, mais de 366 mil videoconferências foram realizadas no âmbito do Poder Judiciário e 19.616 salas de reuniões foram criadas. Em alguns tribunais, como é o caso do TJMG, registrou-se um aumento de $40 \%$ da produtividade.

\footnotetext{
${ }^{17}$ AGÊNCIA BRASIL. Um em cada 4 brasileiros não tem acesso à internet, mostra pesquisa. Disponível em: https://agenciabrasil.ebc.com.br/economia/noticia/2020-04/um-em-cada-quatro-brasileiros-nao-tem-acessointernet\#: :text=A\%20Pesquisa\%20Nacional\%20por\%20Amostra,n\%C3\%A3o\%20tem\%20 cesso\%20\%C3\%A0\%20internet. Acesso em 29 set. 2020.

${ }_{18}$ Disponível em: < https://www.anatel.gov.br/consumidor/component/content/article/109-manchetes/981confira-o-balanco-semestral-de-reclamacoes-registradas-na-anatel>. Acesso em 28 set. 2020.

19 ALVES, Lucélia de Sena; SOARES, Carlos Henrique. Audiência telepresencial e devido processo constitucional. No prelo.

${ }^{20}$ Seminário promovido pelo Conselho Nacional de Justiça, em 7 de agosto de 2020, em seu canal no Youtube. Disponível em 〈https://www.youtube.com/watch?v=XI3bgkBRSTA〉. Acesso em 14 set. 2020.
} 
Entretanto, o aumento da produtividade deve ser analisado criteriosamente. Enquanto magistrados e órgãos do Poder Judiciário comemoram os resultados promovidos pelas plataformas virtuais, advogados apontam algumas questões a serem aprimoradas, com base em experiências nas audiências telepresenciais.

Serão analisados criticamente dois casos apresentados pela mídia recentemente.

Recentemente, foi noticiado que a juíza da $2^{\mathrm{a}}$ Vara do Trabalho de Cabo Frio (RJ) silenciou o microfone de um advogado, enquanto ele se manifestava em uma audiência por videoconferência. Segundo foi noticiado, o advogado Marcos Chehab Maleson teve o microfone silenciado "enquanto fazia uso autorizado da palavra para pedir que fosse registrado em ata ofato de uma das testemunhas da outra parte estar acompanhada durante a oitiva" 21 . A justificativa para o ato foi no sentido de que a audiência estaria sendo gravada e que os requerimentos do advogado não precisariam ser registrados no termo de audiência.

Em que pese a justificativa da magistrada do caso narrado, não há qualquer relação entre o fato de as audiências estarem sendo gravadas e o direito de o advogado solicitar o registro, no termo de audiência, dos motivos pelos quais a prova deveria ser desconsiderada. Isto porque a prova seria registrada pelo documento eletrônico (gravação), mas a argumentação do advogado não, já que seu microfone foi desligado.

O fato de a juíza desligar o microfone do advogado durante a sua fala em audiência por videoconferência violou o contraditório em suas duas garantias: participação e possibilidade de influência na decisão.

Segundo Humberto Theodoro Júnior ${ }^{22}$, devem ficar consignados no termo de audiência: a) as presenças dos sujeitos do processo; b) todos os requerimentos formulados durante os trabalhos; c) as decisões do juiz com relação aos requerimentos; d) o debate oral; e, se for o caso; e) a sentença.

\footnotetext{
${ }^{21}$ Revista Consultor Jurídico. Juíza do RJ desliga microfone de advogado em videoaudiência. Disponível em $\langle$ https://www.conjur.com.br/2020-ago-27/juiza-rj-desliga-microfone-advogado-videoaudiencia $>$. Acesso em 14 set. 2010.

${ }^{22}$ THEODORO JUNIOR, Humberto. Curso de Direito Processual Civil: procedimentos especiais. Vol. I. $60^{\mathrm{a}}$ ed. Rio de Janeiro: Forense, 2019, p. 889.
} 
O termo de audiência possui a função de assegurar a perpetuação da memória do conteúdo do ato processual, bem como facilitar a reapreciação da prova oral produzida quando do eventual exercício do duplo grau de jurisdição ${ }^{23}$.

Conforme prescreve o inciso X, do art. $7^{\circ}$ do Estatuto da Advocacia, é direito do advogado usar da expressão "pela ordem” em qualquer juízo ou tribunal, mediante intervenção sumária, para esclarecer equívoco ou dúvida surgida em relação a fatos, documentos ou afirmações que influam no julgamento.

Portanto, o ato da juíza de se silenciar o microfone do advogado, representa uma afronta ao devido processo legal constitucional.

Outro caso interessante foi o caso de um escritório de advocacia de São Paulo foi condenado ao pagamento de multa de $5 \%$ do valor da causa $(\mathrm{R} \$ 21.770,00)$ por litigância de má-fé de sua preposta, que teria simulado um problema técnico na videoaudiência de instrução, com o intuito protelatório e de que a sessão fosse redesignada. ${ }^{24}$

Segundo a notícia, a juíza da $62^{\mathrm{a}}$ Vara do Trabalho de São Paulo indeferiu o requerimento do empregador para substituir a audiência virtual pela presencial, depois de a preposta gesticular e reclamar que não estava sendo ouvida. A juíza prosseguiu com a videoaudiência e afirmou que poderia ouvir a preposta no dia seguinte, dando tempo para corrigir seu áudio. Pouco depois, a preposta conseguiu habilitar o áudio, e a audiência de instrução seguiu.

Sobre este caso, por mais que a magistrada possa ter tido indícios da má-fé da preposta, sem estar presente ao local em que ela se encontrava, nunca será possível se certificar da veracidade das suspeitas.

Conforme exposto, o número de reclamações da ANATEL pelas falhas dos serviços de banda larga é crescente a aumentou sobremaneira durante a pandemia.

\footnotetext{
${ }^{23}$ CÂMARA, Alexandre Freitas. Atos de cooperação judiciária devem ser documentados (e o Enunciado 687 do FPPC). Disponível em: <https://www.conjur.com.br/2019-abr-10/alexandre-camara-documentacao-atoscooperacao-judiciaria\# ftn2>. Acesso em 14 set. 2020.

${ }^{24}$ BRASIL. Tribunal Regional do Trabalho da $2^{\mathrm{a}}$ Região. SIMULAR PROBLEMA TÉCNICO DURANTE AUDIÊNCIA VIRTUAL ENSEJA MULTA POR MÂ-FÉ.

Disponível em: < https://ww2.trt2.jus.br/noticias//noticias/noticia/news/simular-problema-tecnico-duranteaudiencia-virtual-enseja-multa-por-ma-

fe/?tx_news_pi1\%5Bcontroller\%5D=News\&tx_news_pi1\%5Baction\%5D=detail\&cHash=c0bb548a9233d08 7 f0624f2be0e6f74a>. Acesso em 29 set. 2020.
} 
Verificamos, portanto, dois problemas: uma possível tentativa de protelar o processo por parte da preposta e uma decisão de aplicação de sanção processual por uma falha não constatada por pessoa que não estava presente no local dos fatos.

Não se pode deixar de citar o importante conceito de vulnerabilidade processual apresentado por Fernanda Tartuce, que leciona:

Vulnerabilidade processual é a suscetibilidade do litigante que o impede de praticar atos processuais em razão de uma limitação pessoal involuntária; impossibilidade de atuar pode decorrer de fatores de saúde e/ou de ordem econômica, informacional, técnica ou organizacional de caráter permanente ou provisório. ${ }^{25}$

As falhas técnicas das redes, por razões alheias à vontade dos sujeitos do processo os colocam na situação de verdadeira vulnerabilidade processual, que deve ser considerada pelo magistrado.

Outro caso interessante ocorreu na Vara do Trabalho de Itaúna/ $\mathrm{MG}^{26}$, em que o magistrado informou às partes, na audiência de conciliação e mediação, em respeito ao princípio da não surpresa que:

o procedimento que será observado na audiência de instrução por videoconferência seguirá o quanto possível os dispositivos aplicáveis a audiências trabalhistas típicas, ou seja, aquelas que eram anteriormente presenciais. Por exemplo: a) no início da audiência, haverá a conferência quanto a estarem participando dela todas as partes e testemunhas, sendo que as testemunhas que não foram ainda ouvidas aguardarão na sala de espera virtual (tal como previsto na plataforma CISCO-WEBEX, sendo que a entrada na sala de audiência virtual será autorizada a tempo e modo), com a ressalva de que se se ausentar nesse tempo de aguardo não será ouvida em outra oportunidade, salvo motivo justificado; b) será exigido que todos os participantes que estão na sala mantenham seus dispositivos de áudio e vídeo abertos, impossibilitando comunicação externa durante o ato; c) o dispositivo de captação de áudio e vídeo deverá ficar em posição tal, no plano máximo possível, que permita enxergar tudo o que esteja em volta do depoente; d) o depoimento será tomado estando o depoente em recinto isolado, ou seja, sem a presença de outras pessoas. Tudo, evidentemente, levando em consideração o contexto do local no qual o depoente se encontrar presencialmente naquele momento.

Há alguns quesitos, como o "b", "c" e "d" devem ser analisados detidamente.

Em relação ao item "b", o fato de os participantes manterem os seus dispositivos de áudio e vídeo abertos não é garantia de que haja a comunicação externa. Imagine-se que alguém esteja participando da audiência pelo celular, mas que atrás do dispositivo, haja um

\footnotetext{
${ }^{25}$ TARTUCE, Fernanda. Igualdade e Vulnerabilidade no Processo Civil. São Paulo: Método, 2012, p. 184.

${ }^{26}$ Caso em que uma das autoras (Lucélia) figurava como advogada de uma das partes e que, diante das restrições de acesso, não se informará o número do processo.
} 
computador com o aplicativo de WhatsApp Web aberto, em que outra pessoa esteja orientando o depoimento.

Quanto ao item "c", infelizmente, as câmeras não são $360^{\circ}$. Não há como fiscalizar o ambiente em que a pessoa participante se encontre de forma integral, por mais que "o máximo de plano possível" seja respeitado.

Por fim, num país como o Brasil, exigir que a testemunha esteja em ambiente isolado, sem o auxílio de qualquer pessoa se demonstra incompatível com a realidade da maior parte dos Brasileiros que não possui conhecimento técnico suficiente para lidarem com as novas tecnologias.

\section{Análise empírica da comunicação entre advogados e os órgãos do Poder Judiciário}

Por iniciativa da Comissão de Processo Civil da OAB Minas Gerais, foi realizada uma pesquisa empírica ${ }^{27}$ com os advogados que atuam no estado, com o intuito de identificar os principais problemas enfrentados pela advocacia, relativos à comunicação entre os advogados e o Poder Judiciário no período de pandemia.

Por meio de questionário eletrônico, a Comissão recebeu respostas às 33 perguntas formuladas, entre os dias 18/06 e 22/06. Participaram efetivamente da pesquisa, 865 advogados.

Analisaremos criticamente alguns dos dados coletados.

Foi perguntado aos advogados qual a sua percepção acerca do eventual atendimento telefônico que tivesse tido com o juízo. Mais de $77 \%$ dos entrevistados informaram que tiveram alguma dificuldade em conseguir contato, sendo que 13,6\% informaram que nunca conseguiram contato.

\footnotetext{
${ }^{27}$ Pesquisa cedida à autora pela Comissão de Processo Civil da OAB/MG. Ainda não publicada.
} 
Revista Eletrônica de Direito Processual - REDP.

Rio de Janeiro. Ano 16. Volume 23. Número 1. Janeiro a Abril de 2022

Periódico Quadrimestral da Pós-Graduação Stricto Sensu em Direito Processual da UERJ

Patrono: José Carlos Barbosa Moreira (in mem.). ISSN 1982-7636. pp. 835-851 www.redp.uerj.br

Qual resposta melhor corresponde à sua experiência de contato por telefone com o Juizo?

493 respostas

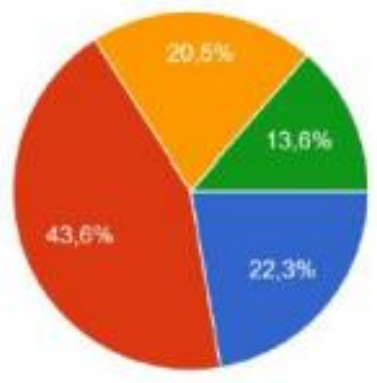

Sempre consegui contato

Algumas vezes consegul contato

Raramente consegui contato

- Nunca consegui contato

Mais de $77 \%$ dos entrevistados informaram que tiveram alguma dificuldade em conseguir contato, sendo que $13,6 \%$ informaram que nunca conseguiram contato.

Em seguida, foi perguntado se o juízo disponibiliza local adequado para a realização dos atos virtuais. Apenas 14,3\% informaram que sim. Mais de 49\% informaram que não.

Nos locais onde você atua, o Poder Judiciário disponibiliza local para acesso ao ambiente virtual e para a realizaçăo dos respectivos atos virtuais?

865 respostas
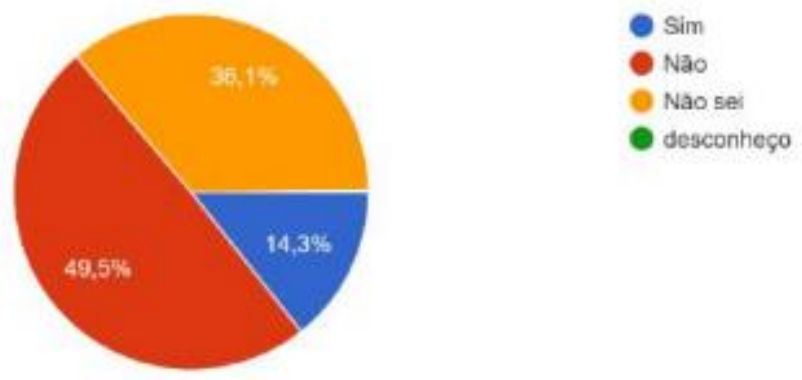

O próximo quadro representa as respostas quanto à garantia da verificação da identidade, por parte do juízo, dos participantes das audiências ou sessões de julgamento. 
Para a realização de algum ato virtual (por exemplo, despacho, audiència, sessão de julgamento, etc), o Juizo tomou alguma providéncia para garant...tituidos nos autos, testemunhas arroladas, etc.)?

64 respostas
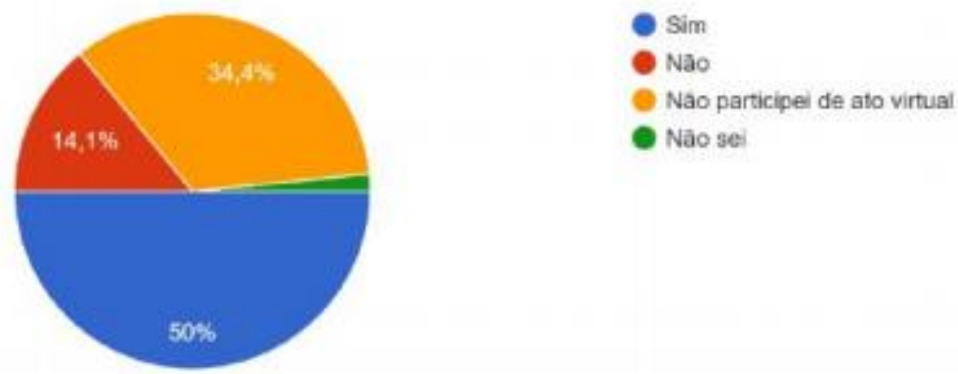

Apenas 50\% dos advogados afirmaram que sim, o juízo verificou a identidade das partes, testemunhas ou patronos participantes, sendo que 14,1\% afirmaram que o juízo não adotou providências para certificar a identidade deles.

As respostas a seguir se referem ao questionamento quanto ao respeito da regra trazida pelo ordenamento jurídico de que a parte não pode assistir ao depoimento pessoal prestado pela outra e de que uma testemunha não tenha acesso ao depoimento das demais.

Em audiência tenha participado, foi adotada alguma forma para evitar que uma parte ou uma testemunha tenha acesso à participação/depoimento da outra? 865 respostas
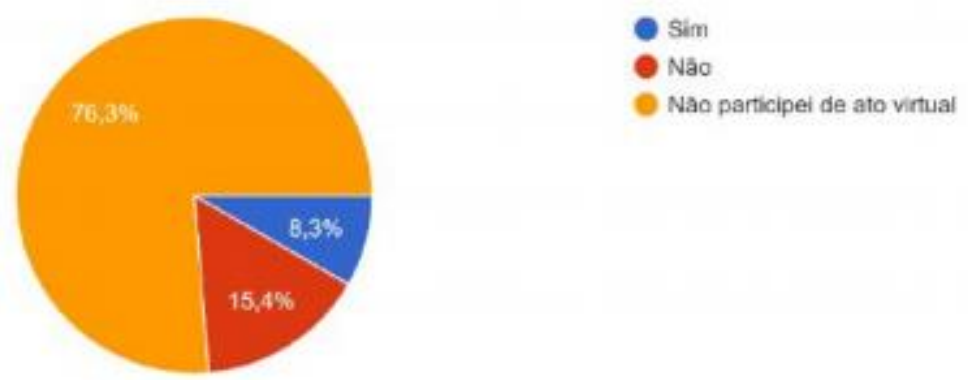

Dos $23,7 \%$ que afirmaram ter participado deste ato virtual, 15,4\% informaram que o juízo não adotou nenhuma providência para que o depoimento de uma parte ou de uma testemunha não fosse assistido pelas demais.

É preciso esclarecer que, embora 865 advogados tenham respondido ao questionário enviado pela Comissão por intermédio do e-mail institucional das 230 (duzentos e trinta) subseções mineiras, em julho de 2020, quando os dados foram coletados, as audiências de 
instrução e julgamento telepresenciais ainda não eram a realidade da justiça comum. Apenas a Justiça do Trabalho estava designando-as.

\section{Considerações Finais}

A ampliação da prática de atos processuais de forma eletrônica promovida em razão da pandemia do Covid-19 demonstrou que pode ser aliada na relação da produtividade dos órgãos do Poder Judiciário.

Entretanto, este avanço não deve ser comemorado sem que se considere a qualidade da atuação dos sujeitos do processo.

Antes que ocorra a implementação do "Juízo 100\% Digital”, é necessário que os sujeitos do processo estejam cientes de que há muito o que se aprimorar no sistema virtual.

As experiências positivas em relação às audiências devem ser agregadas ao sistema de modo a se perpetuar para a realidade pós-pandemia, como é o caso das audiências de conciliação e mediação. As experiências menos felizes, entretanto, devem ser consideradas e analisadas de forma qualitativa para o aprimoramento da operacionalização do sistema de justiça.

Nos casos analisados no presente texto, identificou-se sérias violações ao devido processo constitucional. No caso da $2^{\mathrm{a}}$ Vara do Trabalho de Cabo Frio (RJ) , o fato de a juíza desligar o microfone do advogado durante a sua fala em audiência por videoconferência violou o contraditório em suas duas garantias: participação e possibilidade de influência na decisão. No caso da $62^{\mathrm{a}}$ Vara do Trabalho de São Paulo, a decisão de aplicação de sanção processual por litigância de má-fé se deu por pessoa que não estava presente no local dos fatos e que não possuía mecanismos de aferição da falha no sistema. Quanto ao caso da Vara do Trabalho de Itaúna, o magistrado intima os sujeitos do processo de diversas implicações que podem ocorrer na audiência designada, sem que haja tecnologia suficiente para constatálas.

Com base nos casos e dados apresentados nesta pesquisa, afirma-se que a audiência presencial é a única que se demonstra compatível com o devido processo constitucional, diante das diversas vulnerabilidades processuais identificadas no sistema brasileiro. 
As audiências de instrução e julgamento por videoconferência não devem ser realizadas, diante da sua incompatibilidade com o devido processo constitucional. Conforme demonstrado ao longo do texto, diversas incompatibilidades foram apontadas, como a) a ausência de publicidade; b) dificuldade de manutenção de incomunicabilidade no depoimento pessoal; c) dificuldade de identificação das testemunhas; d) dificuldade de intimação, incomunicabilidade e inquirição das testemunhas; e) valoração da prova pelo magistrado; e f) instabilidade de tráfego de dados. Em tempos de isolamento social, entretanto, diante da impossibilidade de serem realizadas, o magistrado deve optar pelas audiências de instrução e julgamento semipresenciais.

\section{REFERÊNCIAS:}

ABBOUD, Georges. Processo constitucional brasileiro. São Paulo: Revista dos Tribunais, 2016.

AGÊNCIA BRASIL. Um em cada 4 brasileiros não tem acesso à internet, mostra pesquisa. Disponível em: https://agenciabrasil.ebc.com.br/economia/noticia/2020-04/um-emcada-quatro-brasileiros-nao-tem-acessointernet\#: :text=A\%20Pesquisa\%20Nacional\%20por\%20Amostra,n\%C3\%A3o\%2 $\underline{0 \text { tem } \% 20^{\mathrm{a}}}$ cesso\%20\%C3\%A0\%20internet. Acesso em 29 set. 2020.

ALVES, Lucélia de Sena; BORGES, Fernanda Gomes e Souza. As audiências de instrução e julgamento por videoconferência e o devido processo constitucional: uma análise empírica. In ALVES, Lucélia de Sena et al. 4 anos de vigência do Código de Processo de 2015. Belo Horizonte: Editora D’Plácido, 2020.

ALVES, Lucélia de Sena; SOARES, Carlos Henrique. Audiência telepresencial e devido processo constitucional. VirtuaJus, Belo Horizonte, v.5, n. 8, p.301-330, $1^{\circ}$ sem. 2020.

Disponível em: http://periodicos.pucminas.br/index.php/virtuajus/article/view/24455/17128>. Acesso em 05 out. 2020.

ALVES, Lucélia de Sena; SOARES, Carlos Henrique. Audiências telepresenciais na justiça cível e sua compatibilidade com o devido processo constitucional. Disponível em: 
<https://www.migalhas.com.br/depeso/331078/audiencias-telepresenciais-najustica-civel-e-sua-compatibilidade-com-o-devido-processo-constitucional>. Acesso em: 14. Set. 2020.

BAHIA, Alexandre; NUNES, Dierle; PEDRON, Flávio Quinaud. Teoria Geral do Processo. Salvador: Editora JusPodivm, 2020

BRASIL. Tribunal Regional do Trabalho da $3^{\text {a }}$ Região (TRT). Portaria Conjunta n. 11, de 3 de setembro de 2020 .

BRASIL. Conselho Nacional de Justiça. Resolução n. 314/2020. Disponível em: <https://atos.cnj.jus.br/atos/detalhar/3283>. Acesso em 30 set. 2020.

BRASIL. Conselho Nacional de Justiça. Ato normativo $n^{o}$ 0007489-20.2020.00.0000/2020, de 22 de setembro de 2020. Disponível em: < https://www.cnj.jus.br/InfojurisI2/Jurisprudencia.seam?jurisprudenciaIdJuris=5202 $\underline{5 \& \text { indiceListaJurisprudencia }=2 \& \text { tipoPesquisa }=\mathrm{LUCENE} \& \text { firstResult }=0}>. \quad$ Acesso em 05 out. 2020 .

BRASIL. Conselho Nacional de Justiça. Trabalho remoto no Judiciário resultados do uso da plataforma webex - 07 de agosto de 2020. Disponível em <https://www.youtube.com/watch?v=XI3bgkBRSTA>. Acesso em 14 set. 2020.

BRASIL. Tribunal Regional do Trabalho da $2^{\text {a }}$ Região. SIMULAR PROBLEMA TÉCNICO DURANTE AUDIÊNCIA VIRTUAL ENSEJA MULTA POR MÁ-FÉ.

Disponível em: < https://ww2.trt2.jus.br/noticias//noticias/noticia/news/simular-problematecnico-durante-audiencia-virtual-enseja-multa-por-mafe/?tx_news_pi1\%5Bcontroller\%5D=News\&tx_news_pi1\%5Baction $\% 5 \mathrm{D}=$ detail\&

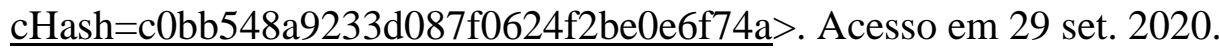

BRÊTAS, Ronaldo de Carvalho Dias. Processo constitucional e Estado Democrático de Direito. 4. ed. Belo Horizonte: Del Rey, 2018.

BRÊTAS, Ronaldo de Carvalho Dias. Fundamentos e inovações do Código de Processo Civil. Belo Horizonte: D’Plácido, 2020.

BORGES, Fernanda Gomes e Souza. A prova no processo civil democrático. Curitiba: Juruá, 2013.

CALMON DE PASSOS, José Joaquim. Direito, poder, justiça e processo: julgando os que nos julgam. Rio de Janeiro: Forense, 2000. 
CÂMARA, Alexandre Freitas. Atos de cooperação judiciária devem ser documentados (e o Enunciado 687 do FPPC). Disponível em: <https://www.conjur.com.br/2019-abr10/alexandre-camara-documentacao-atos-cooperacao-judiciaria\#_ftn2>. Acesso em 14 set. 2020 .

DIDIER JR, Fredie. Curso de Direito Processual Civil. 21. ed. Salvador: JusPodivm, 2019.

DIDIER JÚNIOR, Fredie; BRAGA, Paula Sarno; OLIVEIRA, Rafael Alexandria de. Curso de direito processual civil: teoria da prova, direito probatório, decisão, precedente, coisa julgada e tutela provisória. 13. ed. Salvador: JusPodivm, 2018. v. 2.

GONÇALVES, Aroldo Plínio. Técnica processual e teoria do processo. 2. ed. Belo Horizonte: Del Rey, 2012.

LIMA, Alcides de Mendonça. Audiência de instrução e julgamento, de Athos de Gusmão Carneiro. Revista de Processo. vol. 20. p. 288 - 289. Out - Dez/1980.

TARTUCE, Fernanda. Igualdade e Vulnerabilidade no Processo Civil. São Paulo: Método, 2012.

TARTUCE, Fernanda. Vulnerabilidade processual no Novo CPC. Disponível em: < http://www.fernandatartuce.com.br/wp-content/uploads/2016/01/Vulnerabilidadeno-NCPC.pdf>. Acesso em 23 ago. 2021.

THEODORO JUNIOR, Humberto. Curso de Direito Processual Civil: procedimentos especiais. Vol. I. 60 a ed. Rio de Janeiro: Forense, 2019.

WAMBIER, Luiz Rodrigues; TALAMINI, Eduardo. Curso avançado de processo civil: cognição jurisdicional (processo comum de conhecimento e tutela provisória). 16. ed. Vol. 2. São Paulo: Revista dos Tribunais, 2016. 